\title{
Use of medical services and medicines attributable to type 2 diabetes care in Yaoundé, Cameroon: a cross-sectional study
}

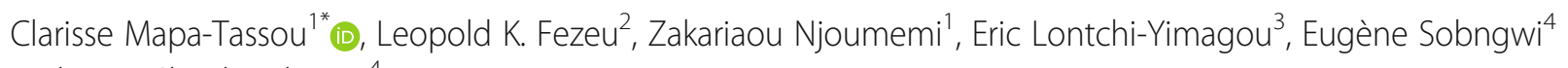
and Jean Claude Mbanya ${ }^{4}$

\begin{abstract}
Background: The increasing numbers of people with type 2 diabetes (T2D) is a global concern and especially in sub-Saharan Africa, where diabetes must compete for resources with communicable diseases. Diabetes intensifies health care utilisation and leads to an increase in medical care costs. However, In Cameroon like in most developing countries, data on the impact of diabetes on the medical health system are scarce. We aimed to analyse the use of medical services and medicines attributable to T2D care in Yaoundé, Cameroon.

Methods: We conducted a cross-sectional study comparing the use of medical services and medicines on 500 people with T2D attending the diabetic outpatient units of three hospitals in Yaounde and 500 people without diabetes matched for age, sex and residence. We performed multivariate logistic and quantile regressions to assess the effect of diabetes on the use of medical services and medicines and the presence of other chronic health problems. Models were adjusted for age, educational level, marital status, occupation and family income.

Results: Overall, the rate of use of health services was found to be greater in people with T2D than those without diabetes. People with T2D had greater odds of having an outpatient visit to any clinician (OR 97.1 [95\% Cl: 41.6-226.2]), to be hospitalised (OR 11.9 [95\% Cl: 1.6-87.9]), to take at least one medicine (OR 83.1 [37.1-185.8]) compared with people without diabetes. We also observed an association between diabetes and some chronic diseases/diabetes complications including hypertension (OR 9.2 [95\% Cl: 5.0-16.9]), cardiovascular diseases (OR 1.9 [95\% Cl: 0.8-4.9]), peripheral neuropathy (OR 6.2 [95\% Cl: 3.4-11.2]), and erectile dysfunction (OR 5.8 [95\% Cl: 2.7-12.1]).

Conclusions: This study showed that the presence of diabetes is associated with an increased use of health care services and medicines as well as with some chronic diseases/diabetes complications.
\end{abstract}

Keywords: Type 2 diabetes, Complications, Medical services, Medicines, Cameroon, Africa

\section{Background}

Diabetes is a challenging problem for public health worldwide with an estimated 415 million people or $8.8 \%$ of adults aged $20-79$ affected in $2015-75 \%$ of whom live in low- and middle-income countries. With current trends, it has been projected that about 642 million people, or one adult in ten, will have diabetes 2040 [1].

\footnotetext{
* Correspondence: mapatassou@yahoo.fr

'Department of Public Health, Faculty of Medicine and Biomedical sciences,

The University of Yaoundé I, Yaoundé, Cameroon

Full list of author information is available at the end of the article
}

The progression of diabetes is part of a broader epidemiological transition from communicable to noncommunicable diseases [2-8]. An estimated 14.2 million adults aged 20-79 have diabetes in Africa, representing a regional prevalence of $2.1-6.7 \%$. Africa has the highest proportion of undiagnosed diabetes; over two thirds (66.7\%) of people with diabetes are unaware they have the disease [1]. Moreover, Africa is facing a health time bomb with diabetes having an increasing impact on people of working age; more than three quarters of deaths due to diabetes in 2015 occurred in people under 
the age of 60 [1]. The burden of diabetes in sub-Saharan Africa is already substantial, and patients with this condition make significant demands on health care resources [9]. In Cameroon, diabetes was not considered a public health priority until after the results of a 2003 epidemiological study revealed that diabetes was a growing potential threat to health [10]. In 2015, the prevalence of diabetes was $5.3 \%$ in the 20 to 79 years age group with more than 14,998 diabetes-related deaths [1]. This transition has been attributed to the population aging, increasingly sedentary lifestyles and obesity $[1,2]$. With the ongoing population aging, it is expected that Africa will continue to experience an increase in the number of patients as well as those with related comorbidities. This is also associated with considerable consequences for health care and related costs [11-18]. The costs associated with diabetes usually include the increased use of health services, loss of productivity and disability. Diabetes therefore imposes a large economic burden on individuals and families, national health systems and nations as a whole, making the disease a significant obstacle to sustainable economic development. Data on the use of resources for diabetes care in sub-Saharan Africa are particularly scarce, difficult to generalize and sometimes outdated, although they all indicate that the diabetes-caused use of medical services and medications is substantial [19-22].

The African Diabetes Impact Study was initiated in sub-Saharan Africa because of the paucity of data on the socio-economic cost of diabetes and the inadequacy of national policies for the prevention and control of diabetes. A Pan African multicentre study was initiated with the purpose of increasing knowledge on type 2 diabetes, with focus on socio-economic aspects. In this study, we aimed to analyse the use of medical services and medicines attributable to T2D care in Yaoundé, Cameroon.

\section{Methods \\ Design}

We conducted a cross-sectional study, comparing the use of medical services and medicines in people with T2D and people without diabetes.

\section{Sample selection \\ Sample size and statistical power}

Data to calculate statistical power for an economic study in sub-Saharan Africa are not available. However, applied to the formula for matched samples [23], results from a similar recently completed study in Shanghai [13] suggest that 500 cases and 500 controls will yield statistically significant results. This sample size also gives > $90 \%$ power to detect a difference in proportions of 10 percentage points or larger at an alpha of 0.05 .

\section{Recruitment of people with type 2 diabetes}

People with T2D were recruited consecutively from outpatient diabetes clinics at three different hospitals in Yaoundé: the Yaoundé Central Hospital, where 80\% of cases were obtained, the Biyem-Assi District Hospital, and the Cité Verte District Hospital. We consecutively interviewed 500 people with T2D attending the outpatient diabetes units of these three hospitals.

\section{Recruitment of people without diabetes}

In order to obtain participants without diabetes comparable to the participants with diabetes, we asked the latter to identify five people living in their neighbourhood who were comparable to them by age $(+/-5$ years) and sex. We therefore contacted and recruited one control subject for each case using this information. Potential controls who said they had been diagnosed with diabetes were excluded. One completed control interview was obtained for each selected person with T2D. All participants were aged between 20 and 80 years.

\section{Data collection}

Trained field workers conducted identical structured face-to-face interviews with all participants in their homes to ascertain recent use of medical care services, medicines and the presence of other chronic diseases using a questionnaire (Additional file 1).

\section{Estimation of the use of medical services}

The study team relied on participants recall to ascertain the use of medical services. To increase accuracy, we limited recall to a 90-day window and, to calibrate the window, we asked respondents to name and associate a well-remembered event that occurred approximately 90 days ago. In order to obtain information on the use of medicines, interviewers asked participants to show to them the medicines they were using. To further increase accuracy, we asked for details only about the most recent hospital outpatient visit, overnight hospitalization, and purchase of each medicine. The study team then used the descriptions of this subset of the most recent events to estimate the characteristics of all events of the same kind, such as reasons for admissions and visits and mean length of hospital stay. Although participants were asked about visits to hospital emergency wards, very few of such visits were reported to support analysis. We therefore excluded data on emergency-ward visits from this report. The recall window for hospitalizations was 365 days. We also enquired about other chronic health conditions such as known complications of diabetes (kidney diseases; erectile dysfunction or loss of libido; amputation of toes, foot, or leg; peripheral neuropathy; depression, eye diseases) and others (cardiovascular diseases, cancer, lung diseases, HIV/AIDS). 


\section{Statistical analyses}

Interview responses were recorded on the paper interview form and subsequently entered into an electronic data base created using the EPI Data version 3.1 software. Prior to analysis, we cleaned variables in the database and discrepancies were then re-checked against the hard-copy records.

Results are expressed as means \pm SD or median (25th - 75th percentiles) and frequencies (percentages) for quantitative and qualitative variables respectively. For univariate analyses, comparisons were made between people with diabetes and people without diabetes using paired Student $t$ tests for continuous variables; McNemar test was used for qualitative variables with fewer than three modalities and a Stuart-Maxwell test for qualitative variables with at least three modalities.

Multivariate logistic and quantile regression models were used to assess the effect of diabetes on the use of medical services, medicines and the presence of other chronic health problems, from which odds ratios (OR) or median regression coefficient were calculated as well as their corresponding 95\% confidence intervals (CI) or their standard errors where appropriate. Models were adjusted for age, educational level, marital status, occupation and family income.

Statistical tests were two-sided. Results were interpreted as significant only when $p$-value were $<0.05$. Statistical analyses were performed using Stata software (version $13.1^{\circ}$, Stata Institute).

\section{Ethical considerations}

Ethical clearance was obtained from the National Ethics Committee for Health Research on Humans of the Ministry of Public Health of Cameroon. Written informed consent was obtained for all participants enrolled.

\section{Results}

\section{Demographics}

Table 1 shows socio-demographic characteristics of the study population. People with T2D and people without diabetes did not differ significantly in terms of gender and Family income. People with T2D were 1.1 years older than people without diabetes $(56.2 \pm 10.7$ years vs. $55.1 \pm 10.6$ years, $p<0.001)$. Compared to people without diabetes, people with T2D were more educated, unemployed and had a bigger family. They were also more often single and a small number of them were smokers. For people with diabetes, the median duration of diabetes was 5 (25th-75th percentiles: $3-10$ ) years.

\section{Use of outpatient services}

Table 2 depicts the self-reported use of medical services. About $90 \%$ of people with T2D and only $12 \%$ of those without diabetes reported having made at least one outpatient hospital visit in the last 90 days $(p<0.001)$. The 90-day median for total visits, among people with T2D, with at least one visit, was 3 (25th -75 th percentiles: $2-4)$ and 1 (25th -75 th percentiles: $1-3$ ) visits for people without diabetes $(p<0.001)$.

Considering visits to any clinician, people with T2D had 97 times more odds to have a visit than those without diabetes (OR 97.1 [95\% CI: 41.6-226.2], $p<0.001$ ). Among people with T2D, outpatient visits did not vary significantly by age or by duration of diagnosed diabetes (all $p>0.05$ ).

\section{Use of inpatient services}

Table 2 shows the use of inpatient services by participants in the two groups. Nine percent of people with T2D reported at least one admission during the preceding 90 days, compared to $0.4 \%$ in the non-diabetic group (OR 10.9 [95\% CI: 1.5-81.6], $p<0.05$ ).

The median hospital length of stay, among those admitted during the preceding 90 days, was 8 (25th-75th percentiles: $5-15)$ for people with T2D and 2 (25th-75th percentiles: 1-3) for those without diabetes. Moreover 47 people with T2D spent at least one night at the hospital during the past year and therefore had 11 times more odds of being hospitalised compared to people without diabetes (OR 11.9 [95\% CI: 1.6-87.9], $p<0.05$ ).

\section{Reasons for inpatient admissions and outpatient visits}

Table 3 shows the reasons for hospital admissions and hospital outpatient visits. About half (53.3\%) of the hospital admissions of people with T2D was attributed to diabetes, $6.7 \%$ to heart diseases and $2.2 \%$ to eye diseases. People with T2D attributed $91.5 \%$ of their most recent hospital outpatient visits to diabetes, while those without diabetes attributed $75.4 \%$ of their visits to other diseases.

\section{Use of medicines}

Nearly all people with T2D (93.6\%) possessed and reported that they were on at least one medication at the time they were interviewed, compared to one-fifth (22.8\%) of people without diabetes, (OR 83.1 [95\% CI: 37.1-185.8]), $p<0.001$. Moreover the use of medicines increased with age and with the duration of diabetes (all $p<0.05)$.

Among people with T2D, $89.6 \%$ were on a glucose lowering agent, $41.6 \%$ on an antihypertensive treatment, $3.2 \%$ on a lipid lowering agent, and $5.6 \%$ on daily aspirin.

\section{Chronic health problems associated with diabetes}

The Table 4 presents the associations between T2D and other chronic health problems. We observed correlations between diabetes and some chronic health 
Table 1 Socio-demographic characteristics of study participants

\begin{tabular}{|c|c|c|c|}
\hline Characteristics & People with T2D & People without diabetes & $p$-value \\
\hline Mean age, mean $\pm S D$ & 56.2010 .7 & $55.11 \pm 10.6$ & $<0.001^{*}$ \\
\hline Age classes, n (\%) & & & $<0.001^{* *}$ \\
\hline$\leq 40$ & $36(7.2)$ & $52(10.4)$ & \\
\hline $41-50$ & $119(23.8)$ & $117(23.4)$ & \\
\hline $51-60$ & $174(34.8)$ & $183(36.6)$ & \\
\hline $61-70$ & $121(24.2)$ & $118(23.6)$ & \\
\hline$>70$ & $50(10)$ & $30(6)$ & \\
\hline Gender, n (\%) & & & $1^{* * *}$ \\
\hline Male & $241(48)$ & $241(48)$ & \\
\hline Female & $259(51.8)$ & $259(51.8)$ & \\
\hline Diabetes duration, years median $\left(1^{\text {st }}-3^{\text {rd }}\right)$ & $5(3-10)$ & - & - \\
\hline \multicolumn{4}{|l|}{ Diabetes duration, years } \\
\hline $0-5$ & $268(53.6)$ & & \\
\hline $6-10$ & $98(19.6)$ & & \\
\hline$\geq 11$ & $134(26.8)$ & & \\
\hline Educational level, n (\%) & & & $<0.01^{* *}$ \\
\hline Primary & $238(47.6)$ & $246(49.2)$ & \\
\hline secondary & $190(38)$ & $208(41.6)$ & \\
\hline University & $72(14.4)$ & $46(9.2)$ & \\
\hline Marital status, n (\%) & & & $<0.001^{* * *}$ \\
\hline Not living in couple & $175(35)$ & $158(31.7)$ & \\
\hline Living in couple & $325(65)$ & $341(68.3)$ & \\
\hline Occupation, n (\%) & & & $<0.001^{* * *}$ \\
\hline Working & $227(45.4)$ & $279(55.8)$ & \\
\hline Not working & $273(54.6)$ & $221(44.2)$ & \\
\hline Not working because of ill, n (\%) & $36(7.2)$ & $3(0.6)$ & $<0.001^{* * *}$ \\
\hline Family size, mean (SD) & $6.81(3.6)$ & $5.59(2.9)$ & $<0.001^{*}$ \\
\hline Family income, USD/person/year median $\left(1^{\text {st }}-3^{\text {rd }}\right)^{\text {a }}$ & $2400(1440-4800)$ & $2400(1380-3600)$ & $>0.05^{*}$ \\
\hline Tobacco smoking, n (\%) & & & $<0.001^{* *}$ \\
\hline Never smoked & $400(80)$ & $342(68.4)$ & \\
\hline Ex-smoker & $85(17)$ & $49(9.8)$ & \\
\hline Current smoker & $15(3)$ & $109(21.8)$ & \\
\hline
\end{tabular}

${ }^{*} p$-values from paired $t$-test; ${ }^{* *} p$-values from Stuart-Maxwell test and ${ }^{* * *} p$-values from McNemar test

${ }^{a}$ Family income was available only for 204 persons with diabetes and 173 persons without diabetes. Mean annual family income per person is the monthly respondent's self-reported family income times 12 months. 1 USD $=500$ XAF. USD United States Dollar

diseases. People with T2D had more odds of having hypertension (OR 9.2 [95\% CI: 5.0-16.9]), cardiovascular diseases (OR 1.9 [95\% CI: 0.8-4.9]), peripheral neuropathy (OR 6.2 [95\% CI: 3.4-11.3]), and erectile dysfunction (OR 5.8 [95\% CI: 2.7-12.2]) compared to those without diabetes $(p<0.01)$. More than $86 \%$ of people with diabetes had at least one comorbidity or complication. No statistical association was observed between the proportions of cancer, HIV/AIDS, lung, kidney and eyes-related diseases in the two groups.

\section{Discussion}

Diabetes imposes a large economic burden on the national healthcare system. The estimation of the impact of T2D on the use of health services and medicines by people with $\mathrm{T} 2 \mathrm{D}$ is an indicator of this burden. In Cameroon, there is a limited data on the impact of T2D on the healthcare system. In this study, in order to assess the use of medical services, medicines and the presence of chronic health conditions, we conducted a crosssectional study comparing the outcomes in a group of 
Table 2 Use of medical services and medicines by the study population

\begin{tabular}{|c|c|c|c|c|c|}
\hline Use of services & $\begin{array}{l}\text { People } \\
\text { with T2D }\end{array}$ & $\begin{array}{l}\text { People without } \\
\text { diabetes }\end{array}$ & OR $(95 \% C l)^{a}$ & $\begin{array}{l}\text { median } \\
(95 \% \mathrm{Cl})\end{array}$ & $p$-value \\
\hline \multicolumn{6}{|l|}{ Use of outpatient services } \\
\hline $\begin{array}{l}\text { Estimated percentage of people with at least } 1 \text { visit to hospital, } \\
\text { last } 90 \text { days, } n(\%)\end{array}$ & $485(97)$ & $70(14)$ & 267.6 (83.9-854.2) & - & $<0.001$ \\
\hline $\begin{array}{l}\text { Estimated percentage of people with at least } 1 \text { outpatient visit } \\
\text { to hospital, last } 90 \text { days, } n(\%)\end{array}$ & $454(90.8)$ & $60(12)$ & $129.8(58.1-289.9)$ & - & $<0.001$ \\
\hline $\begin{array}{l}\text { Median outpatient visits at the hospital per person, among those } \\
\text { with at least } 1 \text { outpatient visit during the last } 90 \text { days, median }\left(1^{\text {st }}-3^{\text {rd }}\right)\end{array}$ & $3(2-4)$ & $1(1-2)$ & - & $1.5(0.7-2.3)$ & $<0.01$ \\
\hline $\begin{array}{l}\text { Estimated percentage of people with at least } 1 \text { outpatient visit to } \\
\text { any clinician, last } 90 \text { days, } \mathrm{n}(\%)\end{array}$ & $460(92)$ & $98(19.6)$ & $97.1(41.6-226.2)$ & - & $<0.001$ \\
\hline $\begin{array}{l}\text { Median total outpatient visits to any clinician, last } 90 \text { days, median } \\
\left(1^{\text {st }}-3^{\text {rd }}\right)\end{array}$ & $3(1-4)$ & $0(0-0)$ & - & $2(1.8-2.2)$ & $<0.001$ \\
\hline \multicolumn{6}{|l|}{ Use of inpatient services } \\
\hline $\begin{array}{l}\text { Estimated percentage of people with at least } 1 \text { inpatient admission, } \\
\text { last } 90 \text { days, } \mathrm{n}(\%)\end{array}$ & $45(9)$ & $2(0.4)$ & $10.9(1.5-81.6)$ & - & $<0.05$ \\
\hline $\begin{array}{l}\text { Median length of stay, most recent hospital admission, if admitted } \\
\text { last } 90 \text { days, median }\left(1^{\text {st }}-3^{\text {rd }}\right)\end{array}$ & $8(5-15)$ & $2(1-3)$ & - & $9.17(-28.2-9.9)$ & NS \\
\hline $\begin{array}{l}\text { Estimated annual percentage of people with at least } 1 \text { inpatient } \\
\text { admission, } n(\%)\end{array}$ & $47(9.4)$ & $3(0.6)$ & $11.9(1.6-87.9)$ & - & $<0.05$ \\
\hline \multicolumn{6}{|l|}{ Use of medicines } \\
\hline Estimated percentage of people with at least one medicine, $\mathrm{n}(\%)$ & 468 (93.6) & $114(22.8)$ & $83.1(37.1-185.8)$ & - & $<0.001$ \\
\hline
\end{tabular}

500 people with T2D and 500 people without diabetes in Yaoundé, matched for age (+/- 5 years), sex and residence.

People with T2D and people without diabetes did not differ on gender and residence. People with T2D were 1.1 years older than people without diabetes. We observed a statistically significant difference in the matching criterion age which probably results from the frequency matching using 5-year age bands. In order to adjust for socio-demographic characteristics, analyses were adjusted for age, educational level, marital status, occupation and family income.

Table 3 Self-reported causes of inpatient admissions and outpatient visits

\begin{tabular}{|c|c|c|c|}
\hline \multirow[t]{2}{*}{ Reason } & \multirow{2}{*}{$\begin{array}{l}\text { Inpatient } \\
\text { admissions } \\
\text { People with T2D } \\
\text { n (\%) }\end{array}$} & \multicolumn{2}{|c|}{ Hospital outpatient visits } \\
\hline & & $\begin{array}{l}\text { People with T2D } \\
\text { n (\%) }\end{array}$ & $\begin{array}{l}\text { People without } \\
\text { diabetes } \\
\mathrm{n}(\%)\end{array}$ \\
\hline Diabetes & $24(53.3)$ & $455(91.5)$ & $0(0)$ \\
\hline Lung diseases & $5(11.1)$ & $0(0)$ & $2(3.3)$ \\
\hline Heart diseases & $3(6.7)$ & $6(1.2)$ & $9(14.7)$ \\
\hline Eyes diseases & $1(2.2)$ & $7(1.4)$ & $3(0.6)$ \\
\hline Kidney diseases & $0(0)$ & $3(0.6)$ & $1(1.6)$ \\
\hline Trauma & $0(0)$ & $1(0.2)$ & $0(0)$ \\
\hline Other & $12(26.7)$ & $7(1.4)$ & $46(75.4)$ \\
\hline
\end{tabular}

People with T2D had 97 times more odds of having an outpatient visit to any clinician, 11 times more odds of being hospitalised and 83 times more odds of being on at least one medicine, compared with people without diabetes. Considering the proportions, $92 \%$ of people with T2D reported at least one outpatient visit during the preceding 90 days, compared to $19.6 \%$ of people without diabetes. Also, $9.4 \%$ of people with T2D reported at least one inpatient admission compared to $0.4 \%$ for people without diabetes. Finally, with regards to the use of medicines, $93.6 \%$ of people with T2D were on at least one medication compared to $22.8 \%$ for people without diabetes.

These proportions are much higher than those observed in a study using a similar interview schedule design in China, where the proportions from people with T2D were $46.1 \%$ for outpatient visits, $3.6 \%$ for inpatient days and $66.2 \%$ for medicines; compared to $23.3 \%, 1.6 \%$ and $18.3 \%$ respectively for people without diabetes [13]. Also, in a multi-centric study in Africa including Cameroon and 3 other countries (Mali, Tanzania and South Africa), the overall proportions were also as high as in Cameroon; the proportions from people with T2D were $90.5 \%$ for outpatient visits, $4.9 \%$ for inpatient visits, $94.8 \%$ for ongoing medication; compared to $15.4,1.1$ and $26.6 \%$ respectively for people without diabetes [12].

Several factors could explain these differences. One important factor is that unlike in a comparable study in China where diabetes was ascertained by a population- 
Table 4 Health chronic problems declared by the study population

\begin{tabular}{|c|c|c|c|c|c|}
\hline Chronic diseases & $\begin{array}{l}\text { People with T2D } \\
\text { n (\%) }\end{array}$ & $\begin{array}{l}\text { People without diabetes } \\
\text { n (\%) }\end{array}$ & $p$-value ${ }^{*}$ & $\mathrm{OR}(95 \% \mathrm{Cl})^{* *}$ & $p$-value $* *$ \\
\hline Hypertension & $250(50.1)$ & $79(15.8)$ & $<0.001$ & $9.2(5.0-16.9)$ & $<0.001$ \\
\hline Cardiovascular diseases & $47(9.4)$ & $21(4.2)$ & $<0.01$ & $1.9(0.8-4.9)$ & $<0.01$ \\
\hline Peripheral neuropathy & $271(54.2)$ & $117(23.5)$ & $<0.001$ & $6.2(3.4-11.3)$ & $<0.001$ \\
\hline Erectile dysfunction or loss of libido & $143(29.3)$ & $52(10.4)$ & $<0.001$ & $5.79(2.7-12.2)$ & $<0.001$ \\
\hline Foot or leg ulcer/Amputation & $30(6)$ & $9(1.8)$ & $<0.001$ & $2.5(0.7-8.4)$ & $>0.05$ \\
\hline Kidney diseases & $39(7.8)$ & $18(3.6)$ & $<0.01$ & $0.8(0.3-2.3)$ & $>0.05$ \\
\hline Eyes diseases & $49(9.8)$ & $21(4.2)$ & $<0.001$ & $1.6(0.7-3.4)$ & $>0.05$ \\
\hline Depression & $25(5)$ & $7(1.4)$ & $<0.01$ & $7.6(1.4-65.9)$ & $>0.05$ \\
\hline Cancer & $5(1)$ & $3(0.6)$ & 0.7 & - & - \\
\hline Lung diseases & $28(5.6)$ & $27(5.4)$ & 1 & $0.8(0.3-2.1)$ & $>0.05$ \\
\hline HIV/AIDS ${ }^{a}$ & $5(1)$ & $6(1.2)$ & 1 & $0.8(0.2-3.8)$ & $>0.05$ \\
\hline Comorbidity number & & & $<0.001^{* * *}$ & & \\
\hline 0 & 68 (13.6) & $194(38.8)$ & & & \\
\hline 1 & $122(24.4)$ & $174(34.8)$ & & & \\
\hline$\geq 2$ & $310(62)$ & $132(26.4)$ & & & \\
\hline
\end{tabular}

${ }^{*} p$-value from paired $t$-test; ${ }^{* *} \mathrm{OR}$ and $p$-value from multivariate logistic regression; ${ }^{* *} p$-value from the Stuart-Maxwell test

aHIV/AIDS: Human Immunodeficiency Virus infection and Acquired Immune Deficiency Syndrome

based household screening, a majority of diabetes cases remain undiagnosed in Africa [24]. In Africa, testing for diabetes usually occurs after patients present with complications known to arise from diabetes [24]. This means that, as a group, people recognized as having diabetes in Africa are much sicker than their counterparts in many other places, and need more services and medication.

The under-utilization of medical services by the general population is another cause of the big differences we report. Medical care in Africa is often very expensive relative to income [24]. People with diabetes may receive more drugs because their condition brings them into frequent contact with the health care system, increasing both the likelihood of detecting and treating previously undiagnosed diseases and the continuation of medication for known chronic disorders.

A third cause is the fact that people with T2D were recruited from well-organized diabetes clinics located in the capital, with a high concentration of general practitioners, internists and diabetologists. Findings would likely to be different if people with diabetes from other parts of the country were included in the study.

Furthermore, diabetes was associated with several comorbidities. We observed associations between diabetes and other chronic conditions such as hypertension, cardiovascular diseases, peripheral neuropathy, and erectile dysfunction. This probably increases the burden on people with diabetes. Indeed, it is known that the number of comorbidities is a strong predictor for the volume of medical health care utilisation [20, 24-27].
This study has some limitations. Firstly, as it is neither possible nor desirable to affect diabetes experimentally, our research design was observational. However, our cross-sectional study with a comparison group is the most widely used approach and accepted measure of the economic and social impacts of diabetes [11, 14, 15, 28-30]. Secondly, the sample consisted of consecutive users of the outpatient diabetic clinics of hospitals in the capital city, a procedure that probably over-selected people with diabetes who were more ill and more likely to use and more likely to be able to afford the services. Also, the self-reported information raises the likelihood of recall bias but we tried to limit this by considering 3 months for outpatient visits and 1 year for hospitalization. Literature in industrialized countries suggests that patients can remember occurrences and many details of meetings of medical care for those no older than 3 months, and remember the occurrence and even hospitalization details for up to 1 year [25-27, 31, 32]. To the extent that the patient cannot recall, it does usually develop in the direction of under-reporting, particularly during outpatient visits $[31,32]$. Any underreporting in our data should have the effect of skewing downwards the estimates of the effects of diabetes on the use of medical care, because the people with T2D had significantly more encounters than people without diabetes.

\section{Conclusion}

In conclusion, this study showed that, people with T2D in Cameroon use more resources (outpatient visits, 
hospitalizations and medicines) than people without diabetes. Although non-communicable diseases like diabetes are commonly thought to be minor problems for health systems and patients in Africa compared to communicable diseases, there can be no doubt that diabetes imposes a significant burden on families and the health care system in Cameroon. This therefore mandates that the attention of policymakers should be drawn and actions informed by evidence should be considered.

\section{Additional file}

Additional file 1: African DM Study impact questionnaire18. IIness Impact interview. This study compared people with and without type 2 diabetes from the same neighbourhoods matched by age and sex. Data was obtained by personal interviews using the Diabetes Impact questionnaire developed by the International Diabetes Federation for Africa. Except for a limited number of questions about diabetes treatment applicable only to the group of patients with diabetes, both groups responded to identical questions. These were divided into 4 categories as follows: Health Utility Index 3, Use of medical services, Impact of health problems and Medications. This study focuses only on the component related to the use of medical services. Most of the questions elicited information on respondents' use of health services (outpatient visits and hospitalizations) during the period of 3 months leading up to the study as well as any medicines they were taking at the time of the interview. We also asked questions about any prevailing health conditions. (PDF $110 \mathrm{~kb}$ )

\section{Acknowledgments}

We thank all the field workers involved in this study and acknowledge the valuable contribution of the International Diabetes Federation- task force on diabetes health economics.

\section{Funding}

This study was funded by allocations from the Economic Study Fund of the International Diabetes Federation.

\section{Availability of data and materials}

The datasets used and/or analysed during the current study available from the corresponding author on a reasonable request.

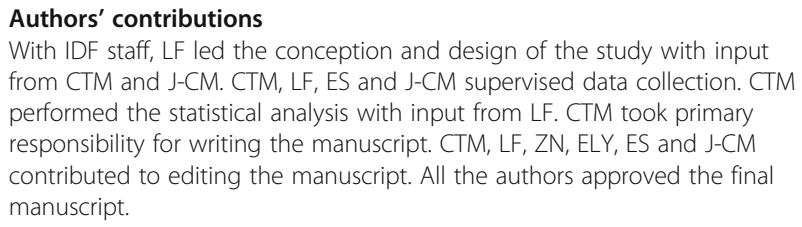

\section{Competing interests}

The authors declare that they have no competing interests.

\section{Consent for publication \\ Not applicable.}

\section{Ethics approval and consent to participate}

Ethical approval was given by the National Ethics Committee for Health Research on Humans of the Ministry of Health of Cameroon. Reference number: No075/CNE/DNM/08.

Written informed consent was obtained for all participants enrolled.

\section{Publisher's Note}

Springer Nature remains neutral with regard to jurisdictional claims in published maps and institutional affiliations.

\section{Author details}

'Department of Public Health, Faculty of Medicine and Biomedical sciences, The University of Yaoundé I, Yaoundé, Cameroon. ' University of Paris 13, Sorbonne Paris Cité - UREN (Unité de Recherche en Epidémiologie Nutritionnelle), U557 Inserm; U1125 Inra; Cnam; CRNH IdF, F-93017 Bobigny, France. ${ }^{3}$ Diabetes Research and Training Centre and Division of Endocrinology, Department of Medicine, Albert Einstein College of Medicine, Bronx, New York, USA. ${ }^{4}$ Department of Internal Medicine and specialties, Faculty of Medicine and Biomedical sciences, The University of Yaoundé I, Yaoundé, Cameroon.

Received: 10 November 2016 Accepted: 29 March 2017

Published online: 11 April 2017

\section{References}

1. International Diabetes Federation. IDF Diabetes. 7th ed. Brussels: International Diabetes Federation; 2015.

2. Miranda JJ, Kinra S, Casas JP, Smith GD, Ebrahim S. Non-communicable diseases in low- and middle-income countries: context, determinants and health policy. Trop Med Int Health TM IH. 2008;13:1225-34.

3. McKeown RE. The epidemiologic transition: changing patterns of mortality and population dynamics. Am J Lifestyle Med. 2009;3:19S-26S.

4. Gage TB. Are modern environments really bad for us?: revisiting the demographic and epidemiologic transitions. Am. J. Phys. Anthropol. 2005; Suppl 41:96-117

5. Kirk D. Demographic transition theory. Popul Stud. 1996;50:361-87.

6. Omran AR. The epidemiologic transition. A theory of the epidemiology of population change. Milbank Mem. Fund Q. 1971;49:509-38.

7. Omran AR. The epidemiologic transition theory. A preliminary update. J Trop Pediatr. 1983;29:305-16.

8. Olshansky SJ, Ault AB. The fourth stage of the epidemiologic transition: the age of delayed degenerative diseases. Milbank Q. 1986;64:355-91.

9. Unwin N, Setel P, Rashid S, Mugusi F, Mbanya JC, Kitange H, et al. Noncommunicable diseases in sub-Saharan Africa: where do they feature in the health research agenda? Bull World Health Organ. 2001;79:947-53.

10. HoPiT. Cameroon burden of Diabetes (CamBod) Project. Yaoundé,Cameroon; 2004.

11. Brown JB, Nichols GA, Glauber HS, Bakst AW. Type 2 diabetes: incremental medical care costs during the first 8 years after diagnosis. Diabetes Care. 1999;22:1116-24.

12. Brown JB, Ramaiya K, Besançon S, Rheeder P, Tassou CM, Mbanya J-C, et al. Use of medical services and medicines attributable to diabetes in SubSaharan Africa. PLoS One. 2014;9:e106716.

13. Yang W, Zhao W, Xiao J, Li R, Zhang P, Kissimova-Skarbek K, et al. Medical care and payment for diabetes in China: enormous threat and great opportunity. PLoS One. 2012;7:e39513.

14. Selby JV, Ray GT, Zhang D, Colby CJ. Excess costs of medical care for patients with diabetes in a managed care population. Diabetes Care. 1997; 20:1396-402.

15. Jönsson B. The economic impact of diabetes. Diabetes Care. 1998;21 Suppl 3:C7-10.

16. Norlund A, Apelqvist J, Bitzén PO, Nyberg P, Scherstén B. Cost of illness of adult diabetes mellitus underestimated if comorbidity is not considered. J Intern Med. 2001;250:57-65.

17. Westert GP, Satariano WA, Schellevis FG, van den Bos GA. Patterns of comorbidity and the use of health services in the Dutch population. Eur J Public Health. 2001;11:365-72.

18. Struijs JN, Baan CA, Schellevis FG, Westert GP, van den Bos GAM. Comorbidity in patients with diabetes mellitus: impact on medical health care utilization. BMC Health Serv Res. 2006;6:84.

19. Chale S, Swai A, Mujinja P, McLarty D. Must diabetes be a fatal disease in Africa? Study of costs of treatment. BMJ. 1992;304:1215-8.

20. Beran D, Yudkin JS. Diabetes care in sub-Saharan Africa. Lancet Lond Engl. 2006;368:1689-95.

21. Nkegoum A. Coût direct et indirect du diabète en l'absence de complications chroniques a Yaounde'. Cameroun: University of Yaoundé l; 2002.

22. World Health Organization. Global report on diabetes. Geneva: World Health Organization; 2016.

23. Campbell MJ, Julious SA, Altman DG. Estimating sample sizes for binary, ordered categorical, and continuous outcomes in two group comparisons. BMJ. 1995;311:1145-8. 
24. Mbanya JCN, Motala AA, Sobngwi E, Assah FK, Enoru ST. Diabetes in subSaharan Africa. Lancet. 2010;375:2254-66.

25. Raina P, Torrance-Rynard V, Wong M, Woodward C. Agreement between self-reported and routinely collected health-care utilization data among seniors. Health Serv Res. 2002;37:751-74.

26. Roberts RO, Bergstralh EJ, Schmidt L, Jacobsen SJ. Comparison of selfreported and medical record health care utilization measures. J Clin Epidemiol. 1996:49:989-95.

27. Brown JB, Adams ME. Patients as reliable reporters of medical care process. Recall of ambulatory encounter events. Med. Care. 1992;30:400-11.

28. American Diabetes Association. Economic costs of diabetes in the U.S. in 2012. 2013. p. 1033-46.

29. Köster I, von Ferber L, Ihle P, Schubert I, Hauner H. The cost burden of diabetes mellitus: the evidence from Germany-the CoDiM study. Diabetologia. 2006;49:1498-504

30. Jo C. Cost-of-illness studies: concepts, scopes, and methods. Clin Mol Hepatol. 2014;20:327-37.

31. Wolinsky FD, Miller TR, An H, Geweke JF, Wallace RB, Wright KB, et al. Hospital episodes and physician visits: the concordance between selfreports and medicare claims. Med Care. 2007:45:300-7.

32. Zuvekas SH, Olin GL. Validating household reports of health care use in the medical expenditure panel survey. Health Serv Res. 2009:44:1679-700.

Submit your next manuscript to BioMed Central and we will help you at every step:

- We accept pre-submission inquiries

- Our selector tool helps you to find the most relevant journal

- We provide round the clock customer support

- Convenient online submission

- Thorough peer review

- Inclusion in PubMed and all major indexing services

- Maximum visibility for your research

Submit your manuscript at www.biomedcentral.com/submit
Biomed Central 